\title{
Patterns and determinants of breastfeeding and complementary feeding practices of Emirati Mothers in the United Arab Emirates
}

\author{
Hadia Radwan ${ }^{1,2}$
}

\begin{abstract}
Background: Breastfeeding is the preferred method of feeding for the infant. The present study aimed at investigating the different infant feeding practices and the influencing factors in the United Arab Emirates (UAE).

Methods: A convenient sample of 593 Emirati mothers who had infants up to 2 years of age was interviewed. The interviews included a detailed questionnaire and conducted in the Maternal and Child Health Centers (MCH) and Primary Health Centers (PHC) in three cities.

Results: Almost all the mothers in the study had initiated breastfeeding (98\%). The mean duration of breastfeeding was 8.6 months. The initiation and duration of breastfeeding rates were influenced by mother's age $(P<0.034)$ and education $(P<0.01)$, parity $(O R=2.13 ; P<0.001)$, rooming in $(O R=21.70 ; P<0.001)$, nipple problem $(P<0.010)$ and use of contraception $(P<0.034)$. As for the feeding patterns, the results of the multiple logistic analyses revealed that rooming in $(\mathrm{OR}=4.48 ; \mathrm{P}<0.001)$, feeding on demand $(\mathrm{OR}=2.29 ; \mathrm{P}<0.005)$ and feeding more frequently at night $(\mathrm{P}<0.001)$ emerged as significant factors associated with exclusive or predominantly breastfeeding practices. Among the 593 infants in the study, 24.1\% had complementary feeding, 25\% of the infants were exclusively breastfed, and $49.4 \%$ were predominantly breastfed since birth. About $30 \%$ of the infants were given nonmilk fluids such as: Anis seed drink (Yansun), grippe water and tea before 3 months of age. The majority of the infants (83.5\%) in the three areas received solid food before the age of 6 months. A variety of reasons were reported as perceived by mothers for terminating breastfeeding. The most common reasons were: new pregnancy (32.5\%), insufficient milk supply (24.4\%) and infant weaned itself (24.4\%).
\end{abstract}

Conclusions: In conclusion, infant and young child feeding practices in this study were suboptimal. There is a need for a national community-based breastfeeding intervention programme and for the promotion of exclusive breastfeeding as part of a primary public health strategy to decrease health risks and problems in the UAE.

Keywords: Breastfeeding, Exclusive breastfeeding, Complementary feeding, Supplementation, United Arab Emirates

\section{Background}

The first two years of life are critical stages for a child's growth and development. Exclusive breastfeeding for six months and continued breastfeeding with safe, appropriate and adequate feeding is recommended as a global health policy in both developing and developed countries [1]. Healthcare standards are considered to be generally high in the United Arab Emirates due to increased

\footnotetext{
Correspondence: zjaziri@eim.ae

'Sr. Nutritionist in Community Nutrition Department, Tawam Hospital, Abu Dhabi, Al Ain, United Arab Emirates

${ }^{2}$ Community Nutrition Department, Tawam Hospital, P.O. Box 17831, Al Ain, United Arab Emirates
}

government spending during strong economic years. Improved standards of living and health services have led to changes in morbidity and mortality rates. The infant mortality rate declined significantly in the UAE. Mortality rate for infants under five in the UAE decreased from 17 per 1000 live birth in 1990 to 8 per 1000 in 2008 [2]. Infectious diseases have gradually declined, and chronic non-communicable diseases (NCD's) are being more prevalent.

It was noted that nutrition-related chronic diseases have increased dramatically in recent years and within a very short period of time; they are the major causes of

\section{Biomed Central}


morbidity and mortality in the UAE (Ministry of Health Report, 2009). Musaiger [3] reported that in addition to changes in lifestyle and physical activities in Middle Eastern countries, the decline in exclusive breastfeeding and high dependence on bottle-feeding are also important factors associated with the increase in the prevalence of obesity. The World Health Organization (WHO) [4] reported that promotion of breastfeeding may contribute to the prevention of childhood obesity. Since breastfeeding represents one of the earliest nutritional experiences of newborns, the first few months after birth may be a critical window for the development of obesity later on in life [5]. In the past few years, several systematic reviews indicated that increases in diseases such as diabetes, obesity and CVD are likely to be caused by a decrease in the practice of breastfeeding [6-8]. The same studies also revealed that these chronic diseases extend beyond infancy and affect the overall health of a nation. This would suggest that obesity prevention begins with breastfeeding.

It should be noted that in Middle Eastern countries, especially in Islamic societies, breastfeeding has a religious basis. Mothers continue to nurse their children for at least two years [9]. However, modernization as well as the aggressive promotion and marketing campaigns of infant formula and other baby food have influenced the traditions of breastfeeding. This resulted in the increased use of bottle-feeding, and mothers ignored the Quranic recommendations of breastfeeding for two years $[10,11]$. In the UAE, limited research reported suboptimal infant feeding practices. Mixed feeding was the norm, and many mothers introduced solid food, liquid food or formula to their infants as early as one month about $50 \%$ of the mothers stopped breastfeeding before their infants reached the age of three months, and 40\% did not even attempt to breastfeed [12]. In 1992, the National Nutrition Survey in the UAE [13] showed that $42 \%$ of mothers gave their children the bottle during the first month, $21 \%$ during the second and 9\% during the third month. Al Mazroui et al. [14] reported that $70 \%$ of infants received non-milk supplements during the first month. In another study in $\mathrm{Al} \mathrm{Ain,} 76.1 \%$ of infants were given milk supplements before the end of their first month, and only $28 \%$ of the mothers exclusively breastfed their infant [15]. In a recent study in the UAE, the exclusive breastfeeding rate was $76.5 \%$ on day one, $48.4 \%$ at one month and $13.3 \%$ at six months [16]. It is worth mentioning that the UAE is a multiethnic, multicultural community. As a consequence, the results of these studies varied and reflected the different breastfeeding practices of all residents, who were from different nationalities, ethnic groups and cultures. These studies did not give an accurate depiction of the breastfeeding practices of local Emirati mothers, about whom the policy makers in the UAE are mostly concerned.
The aim of this study is to evaluate breastfeeding and complementary feeding practices of Emirati mothers in the UAE, and to compare them to the guidelines and recommendations of the World Health Organization.

\section{Methods}

This study was conducted in the $\mathrm{MCH}$ (Maternal and Child Health) and Primary Health Care centers (PHC) centers in Abu Dhabi, Dubai and Al Ain. These centers are homogenous as they are governmental clinics that render maternal and child health services for Emirati mothers for free. Almost all Emirati mothers with children less than five years old visit these centers for the vaccination program for their infants. A multi-stage cluster sampling technique was used to collect data. In the first stage cluster sampling, a list of the $\mathrm{MCH}$ centers within each city was obtained and enumerated with four out of ten centers from each city being selected using simple random sampling. Then a convenient sample of 200 subjects was selected from the four centers from each city with sizes proportionate to sizes of the clinic. Sampling was based on the number of eligible mothers visiting the $\mathrm{MCH}$ centers. The researcher visited the $\mathrm{MCH}$ centers a fixed number of times at different times and days and recruited all eligible mothers. Mothers meeting the inclusion criteria (i.e., Emirati (UAE nationality) with infants less than 2 years of age were interviewed in each city. None of the mothers refused to be interviewed. Each mother signed an informed consent form before they started face to face interview.

\section{Questionnaire}

A pretested questionnaire consisting of 53 questions was used to obtain demographic information such as mother's age, father's and mother's employment, maternal and paternal education level and information about the infant's age, weight, birth order and family size. The survey also gathered information about different feeding practices, such as whether the mothers introduced prelacteal feeds and when solid and liquid supplements were introduced and the nature of these supplements. Mothers were asked how long they breastfed their infants and whether and how often they breastfeed them at night.

Excluding incomplete questionnaires from the 600 interviews, the final sample size included 593 participants.

\section{Definitions}

Feeding patterns were categorized into four groups according to WHO and Labbok and Krasovec $[17,18]$.

- Exclusively breastfeeding: infants only breastfed since birth; no water, formula or liquid supplements.

- Predominately breastfeeding: infants receiving breast-milk and water since birth. 
- Complementary feeding: infants who were mainly breastfed, but infant formula and other liquid or nondairy foods were included in their diet.

- Bottle-feeding: infants who received only formula milk since birth and did not breastfeed.

Other definitions included in this study:

Duration of breastfeeding: the infant's age in months when the mother stopped breastfeeding.

No. of breastfeeds at night: how many times did the mother breastfeed her infant during the night.

Initiation time of first breastfeed: the time at which the mother started breastfeeding after delivery. Early breastfeeding is considered the first feed during the first hour.

Rooming in: placing the infant with the mother after delivery.

Education level was categorized according to school education level:

Illiterate: cannot read or write.

Primary: read and write and have completed elementary education only.

High school: have completed secondary education.

Higher education: have completed higher education than high school.

\section{Data analysis}

The data were analyzed using the Statistical package for Social Sciences (SPSS) version 17 (SPSS Corporation, Chicago, IL). Percentage distributions of sample characteristics were computed to describe the study participants. Comparative statistics were calculated using the Chi square $\left(x^{2}\right)$ test for categorical variables and one-way analysis of variance (ANOVA) for continuous variables as preliminary test. Binary Logistic regression analysis was used to examine the relationship between the initiation time of first breastfeed ( $\leq 1 \mathrm{hr}=1$ or $>1 \mathrm{hr}=0)$, and feeding patterns (Exclusive or almost exclusive breastfeeding $=1$ or not $=0$ ) and a number of characteristics that were identified from the literature as having possible effects on them. The initiation time of first breastfeed is classified as either the mother had initiated breastfeeding within an hour after delivery or after that. While for feeding patterns the dependent variable is classified as either mothers exclusively or predominantly fed their infants or not. Then variables that were significant $(\mathrm{P}<0.05)$ on bivariate analysis were analysed by multiple logistic regression analysis using forward LR selection method.

To compare the association of categorical predictors with the duration of breastfeeding, we use ANOVA whenever the normality and equal variance assumptions are satisfied. Otherwise, we use Kruskal Wallis test. Statistical significance was defined as $\mathrm{P}<0.05$

\section{Ethics}

The Board of the Ethics Committee of the Faculty of Medicine at UAE University and the ethics committee of The University of Teesside-UK approved this study.

\section{Results}

\section{Demographic characteristics}

Table 1 shows the demographic characteristics of the study population. A total of 593 infants (0-2 years) of age, approximately $58 \%$ male and $42 \%$ female were included in this study. The mean infant birth weight was $3.15 \mathrm{~kg}$. The ages of mothers participating in this survey ranged from 17 - 45 years with a mean age of 27.9 years. More than half of the mothers in the three regions have high school education (53.5\%). The majority of the mothers was multiparous (71\%), housewives (84.7\%), practiced rooming in (87.2\%), and delivered normally (83.5\%). Sixty percent of the participants did not use contraception and $88 \%$ of them breastfed their infants upon demand.

\section{Breastfeeding initiation and influencing factors}

In total $98 \%$ of the mothers in this study initiated breastfeeding. Of the mothers who attempted to breastfeed in the hospital, $80.6 \%$ put their infants on their breast within one hour after delivery. While the rest delayed breastfeeding their babies till after one hour postpartum. About three quarters(73\%) of the mothers stated that they did not give their infants any fluids(even water) except breast milk during their stay at the hospital, while the rest of the infants received supplemental fluids with breast milk such as formula milk, water, hospital fluids, crushed dates and yansun drink.

The bivariate analysis of the factors associated with the initiation time of the first breastfeed after delivery is shown in Table 2. It was noted that multiparous mothers were most likely to initiate breastfeeding within an hour than primiparous mothers. Moreover, working mothers were most likely to delay initiation time of the first breastfeeding till after an hour as compared to non working mothers. Mothers who had delivered cesarean section were significantly less likely to initiate first breastfeed within an hour than mothers who had normal delivery. Also infants who were kept with their mothers in the same room after delivery were significantly more likely to be breastfed earlier than infants who were kept in separate room. Infants who had normal birth weight $(2.5-4.0 \mathrm{~kg})$ were most likely to be breastfed earlier than infants with low birth weight $(<2.5 \mathrm{~kg})$. 
Table 1 Percentage distribution of the variables in the study population $(n=593)$

\begin{tabular}{lll}
\hline Variables & No & $\%$ \\
\hline Maternal Age ( years ) ${ }^{* *}$ & & \\
$<25$ & 222 & 37.4 \\
$26-30$ & 211 & 35.6 \\
$31-35$ & 102 & 17.2 \\
$36+$ & 58 & 9.8
\end{tabular}

Mother's employment ${ }^{* *}$

Working

Not working

Mother's education level

Illiterate

Primary

high school

Higher education

Parity**

Primiparous

Multiparous

Delivery method **

Normal

C - section

Types of contraceptive**

None

Non- Hormonal

hormonal

Nipple problems

Yes

No

Infant sex **

Male

Female

Infant birth weight $(\mathrm{kg})$ **

$<2.5$

2-3.0

$3.1-4.0$

$>4.0$

Rooming in ${ }^{* *}$

With the mother

In separate room

Feeding Pattern ${ }^{* *}$

No breastfeeding

Any Breastfeeding

Frequency of breast feeding ${ }^{* * *}$

Upon demand

Scheduled

\section{$\%$}

37.4

35.6

17.2

9.8

\section{3}

84.7

5.7

12.0

53.5

28.5

28.8

71.2

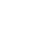

83.5

16.5

29.7

9.6

41.5

58.5

58.2

41.8
Table 1 Percentage distribution of the variables in the study population ( $n=593$ ) (Continued)

No. of breastfeeds at night ${ }^{* *}$

None

19.7

$1-3$

58.3

4-6

Initiation time of first breastfeed

$\leq$ one hour

$>$ one hour

470

* included only infants who were still breastfeeding at the time of study.

** Chi-square analysis, $\mathrm{P}<0.005$.

Table 2 Binary logistic regression for the predictors associated with the initiation time of the first breastfeed $(\mathrm{n}=587)^{1}$

Variables

Infant Sex

No.

$\mathrm{OR}^{*}$

$95 \% \mathrm{Cl}^{* *}$

$P$ value

Male

Female

$340 \quad 1$

Mother's age

$247 \quad 1.23 \quad 0.67-1.51$

$<25$

25-30

30-35

$>35$

60.7 Parity

0.000

Primiparous

Multiparous

$168 \quad 1$

$419 \quad 2.26$

$1.51-3.39$

0.000

Mother's Occupation

0.011

Working

Not working

$91 \quad 1$

$496 \quad 1.090 \quad 1.17-3.08$

0.009

Infant birth weight(kg)

0.001

$<2.5 \mathrm{~kg}$

2.5-3.0

$3.1-4.0$

861

$181 \quad 1.93 \quad 1.11-3.36$

0.019

2892.90

$1.71-4.93$

0.000

$>4.0$

12

0.87

$0.25-2.97$

0.826

Mother's level of education

0.248

49.1

Illiterate

$33 \quad 2.17 \quad 0.79-5.96$

primary

$72 \quad 1.16 \quad 0.62-2.19$

high school

$314 \quad 1.43 \quad 0.93-2.20$

Higher education

1681

Rooming in

0.000

With mother

$517 \quad 17.64 \quad 9.63-32.32$

0.000

1.7

In separate room

$70 \quad 1$

Delivery Method

0.001

Normal

$491 \quad 2.188 \quad 1.36-3.49$

0.001

C- Section

$96 \quad 1$

11.8 *odd ratio ** Confidence interval.

${ }^{1}$ six out of 593 mothers did not attempt to breastfeed their infants. 
Table 3 Factors associated with the duration of breastfeeding * $\left(n=234^{1}\right)$

\begin{tabular}{|c|c|c|c|}
\hline Factors & No. & Duration of breastfeeding Months (mean \pm SD) & $P$ value \\
\hline Infant sex & & & 0.783 \\
\hline Boy & 144 & $8.7 \pm 6.1$ & \\
\hline Girl & 90 & $8.4 \pm 5.6$ & \\
\hline Parity & & & 0.024 \\
\hline Primiparous & 86 & $7.6 \pm 5.0$ & \\
\hline Multiparous & 148 & $9.5 \pm 6.8$ & \\
\hline Mother's age & & & 0.034 \\
\hline$<25$ & 88 & $7.2 \pm 5.1$ & \\
\hline $25-30$ & 77 & $9.7 \pm 7.0$ & \\
\hline $31-35$ & 42 & $9.5 \pm 6.5$ & \\
\hline$>35$ & 27 & $10.0 \pm 6.3$ & \\
\hline Mother's educational level & & & 0.001 \\
\hline Illiterate & 15 & $9.5 \pm 8.3$ & \\
\hline primary & 24 & $13.1 \pm 6.2$ & \\
\hline High school & 124 & $7.6 \pm 5.6$ & \\
\hline Higher Education & 70 & $9.2 \pm 6.0$ & \\
\hline Mother's occupation & & & 0.261 \\
\hline Working & 34 & $8.9 \pm 6.6$ & \\
\hline Not working & 200 & $8.8 \pm 6.2$ & \\
\hline Rooming in & & 0.903 & \\
\hline With the mother & 200 & $8.7 \pm 6.3$ & \\
\hline In Separate room & 34 & $8.9 \pm 5.9$ & \\
\hline Frequency of breastfeeding & & & 0.157 \\
\hline Upon demand & 200 & $8.4 \pm 5.3$ & \\
\hline Schedule & 34 & $7.6 \pm 5.1$ & \\
\hline Nipple problems & & & 0.010 \\
\hline Yes & 95 & $7.5 \pm 5.4$ & \\
\hline No & 139 & $9.7 \pm 6.7$ & \\
\hline Use of contraceptive & & & 0.025 \\
\hline None & 138 & $9.4 \pm 6.1$ & \\
\hline Non Hormonal & 28 & $10.0 \pm 7.3$ & \\
\hline Hormonal & 68 & $7.1 \pm 5.8$ & \\
\hline No. of breastfeeds at night & & & 0.001 \\
\hline None & 87 & $6.1 \pm 5.0$ & \\
\hline $1-3$ & 96 & $9.7 \pm 6.2$ & \\
\hline $4-6$ & 51 & $11.7 \pm 6.4$ & \\
\hline
\end{tabular}

* ANOVA is used whenever the normality and equal variance assumptions are satisfied. Otherwise, we use Kruskal Wallis test.

1 included only infants who were breastfed and stopped breastfeeding at the time of the study.

\section{Breastfeeding duration and influencing factors}

Table 3 shows a number of factors that were associated with breastfeeding duration in this study. It is noted that the mean duration of breastfeeding was $8.6 \pm 5.8$ months. Multiparous Mothers breastfed their infants for a significantly longer period $(9.5 \pm 6.8$ months $)$ than did primiparous mothers $(7.6 \pm 5.0$ months $)(\mathrm{P}<0.024)$. As the mother's age increased, the duration of breastfeeding increased as well: from 7.2 \pm 5.1 months for mothers less than 25 years old to $10.0 \pm 6.3$ months for mothers older than 35 years of age. Mother's education level was significantly related to the breastfeeding duration $(\mathrm{P}<0.001)$; mothers with primary education breastfed for longer periods (13.1 \pm 6.2 months) than did mothers of other educational levels. 
Also, mothers who did not have nipple problems breastfed for significantly longer periods $(9.7 \pm 6.7$ months) than did mothers who suffered from nipple problems (7.5 \pm 5.4 months). Moreover, mothers who either did not use any contraception or used non-hormonal contraception breastfed their infants for a significantly longer period (9.0-10.0 months) than did mothers who used hormonal contraception $(7.1 \pm 5.8$ months $)(\mathrm{P}<0.025)$. In addition, mothers who used to breastfeed more frequently during the night (4-6 times) breastfed their infants significantly longer than did mothers who did not breastfeed their infants during the night (11.7 \pm 6.4 months vs. $6.1 \pm 5.0$ months respectively) $(\mathrm{P}<0.001)$.

\section{Infant feeding patterns}

Infants in the study were categorized, according to their feeding patterns since birth, into four categories: exclusive breastfeeding, predominant breastfeeding, complementary feeding and formula feeding.

Among the 593 infants in this study, 24.1\% had complimentary feeding since birth, and only 10 mothers exclusively bottle-fed their infants (1.7\%). About a quarter of the infants were exclusively breastfeeding and about half of them were predominantly breastfed since birth. The percentage of infants who were either exclusively or predominantly breastfed for 4 or 6 month was calculated, the results showed that $7.4 \%(n=44)$ of the infants were exclusively breastfed for 4 months while only $1.9 \%(\mathrm{n}=11)$ breastfed exclusively for 6 months. Moreover, the percentage of infants who were predominantly breastfed for 4 months was $18.0 \%(n=106)$, and the percentage of infants who were predominantly breastfed for 6 months was $7.1 \%(n=42)$.

\section{Factors influencing breastfeeding practices}

Factors influencing exclusive and predominantly breastfeeding practices were explored using binary logistic regression analysis (Table 4).

The analysis showed that mother's education level, occupation, parity, rooming in, type of delivery, frequency of breastfeeding and the numbers of breastfeeds at night were significant factors associated with exclusive and predominant breastfeeding patterns. Housewives were two times more likely to provide exclusive or predominantly breastfeeding of their infants than working mothers $(\mathrm{OR}=1.89$; $95 \%$ CI 1.17-3.07). Moreover, multiparous mothers were 1.8 times more likely to either exclusively or predominantly breastfeed their infants than primiparous mothers (OR $=1.83$; 95\% CI 1.24-2.71). The odds of either exclusive or predominantly breastfeeding the infants by the mothers who completed either primary or high school educated were about two times compared to the corresponding odds for higher educated mothers. Mothers who delivered normally were more likely to either exclusively or
Table 4 Simple binary logistic regression for the predictors associated with exclusive and predominantly breastfeeding

\begin{tabular}{|c|c|c|c|c|}
\hline Variables & No. & $\mathrm{OR}^{*}$ & $95 \% \mathrm{Cl}^{* *}$ & $P$ value \\
\hline \multicolumn{4}{|l|}{ Infant Sex } & \multirow[t]{3}{*}{0.058} \\
\hline Male & 345 & 1 & & \\
\hline Female & 248 & 0.69 & $0.47-1.01$ & \\
\hline \multicolumn{4}{|l|}{ Mother's age } & \multirow[t]{5}{*}{0.099} \\
\hline$<25$ & 222 & 1 & & \\
\hline $26-30$ & 211 & 0.91 & $0.58-0.43$ & \\
\hline $30-35$ & 102 & 1.66 & $0.99-2.78$ & \\
\hline$>35$ & 58 & 1.43 & $0.76-2.71$ & \\
\hline \multicolumn{4}{|c|}{ Mother's level of education } & \multirow[t]{5}{*}{0.010} \\
\hline Illiterate & 34 & 2.12 & $0.87-5.16$ & \\
\hline Primary & 73 & 2.12 & $1.11-4.07$ & \\
\hline High school & 317 & 1.90 & $1.26-2.87$ & \\
\hline Higher education & 169 & 1 & & \\
\hline \multicolumn{4}{|c|}{ Mother's Occupation } & \multirow[t]{3}{*}{0.009} \\
\hline Working & 90 & 1 & & \\
\hline Not Working & 493 & 1.89 & $1.17-3.07$ & \\
\hline \multicolumn{4}{|c|}{ No. of breastfeeds at night } & \multirow[t]{4}{*}{0.006} \\
\hline None & 117 & 1 & & \\
\hline $1-3$ & 346 & 1.97 & $1.25-3.09$ & \\
\hline $4-6$ & 130 & 2.19 & $1.25-3.84$ & \\
\hline \multicolumn{4}{|l|}{ Parity } & \multirow[t]{3}{*}{0.002} \\
\hline Primiparous & 171 & 1 & & \\
\hline Multiparous & 422 & 1.83 & $1.24-2.71$ & \\
\hline \multicolumn{4}{|l|}{ Rooming in } & \multirow[t]{3}{*}{0.000} \\
\hline with mother & 517 & 5.87 & $3.54-9.75$ & \\
\hline In separate room & 76 & 1 & & \\
\hline \multicolumn{4}{|l|}{ Frequency } & \multirow[t]{3}{*}{0.006} \\
\hline Scheduled & 43 & 1 & & \\
\hline Upon demand & 320 & 2.76 & $1.37-5.52$ & \\
\hline \multicolumn{4}{|l|}{ Nipple problems } & \multirow[t]{3}{*}{0.072} \\
\hline Yes & 246 & 1 & & \\
\hline No & 347 & 1.41 & $0.96-2.07$ & \\
\hline \multicolumn{4}{|l|}{ Type of Delivery } & \multirow[t]{3}{*}{0.001} \\
\hline Cesarean & 98 & 1 & & \\
\hline Normal & 495 & 2.20 & $1.40-3.48$ & \\
\hline \multicolumn{4}{|c|}{ Use of contraception } & \multirow[t]{4}{*}{0.262} \\
\hline None & 360 & 1 & & \\
\hline Non-Hormonal & 176 & 1.18 & $0.58-1.59$ & \\
\hline Hormonal & 57 & 0.83 & $0.43-1.59$ & \\
\hline
\end{tabular}

*odds ratio ** Confidence interval. 
predominantly breastfeed their infants than did those who delivered by cesarean section $(\mathrm{OR}=2.20$; 95\% CI 1.40 3.48). Infants who were breastfed upon demand ( $\mathrm{OR}=$ 2.76; 95\% CI 1.37-5.52) were more likely to be either exclusively or predominantly breastfed than did infants who were breastfed on schedule. Moreover, the odds for mothers who kept their infants with them in the same room after delivery (rooming in) to either exclusively or predominantly breastfeed their infants were six times the corresponding odds for the mothers who kept their infants in separate rooms $(\mathrm{OR}=5.87 ; 95 \% \mathrm{CI} 3.54-9.75)$. Also, the odds for mothers who breastfed their infants at night to either exclusively or predominantly breastfeed their infants were double the corresponding odds for the mothers who did not breastfeed their infants during the night $(\mathrm{P}<0.001)$.

\section{Multiple logistic regression analysis of the variables influencing the infant feeding practices}

In order to identify the most predictive factors in infant feeding practices in this study, only significant variables that were associated with the infant feeding practices in the simple binary logistic test were analysed further using multiple logistic regression models. Rooming in $(\mathrm{OR}=4.48$; 95\% CI 2.14-9.39; $\mathrm{P}<0.001)$, breastfeeding on demand $(\mathrm{OR}=2.92 ; 95 \%$ CI 1.39-6.14; $\mathrm{P}<0.005)$, and breastfeeding at night for $1-3(\mathrm{OR}=3.37$; 95\% CI $1.27-8.96$; $\mathrm{P}<0.015)$ or for 4-6 times each night $(\mathrm{OR}=3.50$; 95\% CI 1.16-10.53; $\mathrm{P}<0.026)$ were the factors that remained in the equation as associated with infant's exclusive or predominantly breastfeeding, allowing for intercorrelation.

\section{Introduction of liquids and solid supplementation Non-milk liquid supplementation}

Mothers were also asked if they gave their infants any traditional drinks or fluid supplements while breastfeeding.

About $70 \%$ of the mothers said that they did not give any fluid supplements to their infants below 3 months of age. However, $15.3 \%$ of the respondents said that they had given grippe water, $10.1 \%$ had given yansun and $2.5 \%$ had given tea to their infants during the first three months of the infant's age.

\section{Milk and solid supplementation}

It is generally recommended by the WHO that solids be introduced to the infants at 6 months of age, as infants are physiologically and developmentally ready for new foods, textures and modes of feeding at this age.

The majority of the infants in this study were introduced to solid foods before the recommended age of 6 months (83.5\%). About 13.5\% of them were given solids, mostly home-made cereals or ready-made cereals, before the age of 3 months (Figure 1).

Mothers were asked to recall the type of foods introduced to their infants as well as the age at which these foods were offered to the infant. Table 5 lists the foods that were introduced to the infants and the mean infant age.

It was noted that the mean infant age $( \pm S D)$ at which formula milk was introduced was $3.8 \pm 3.8$ months. Home made cereals and ready made cereals were introduced to infants at $4.9 \pm 1.7$ months, and $4.6 \pm 1.1$ months

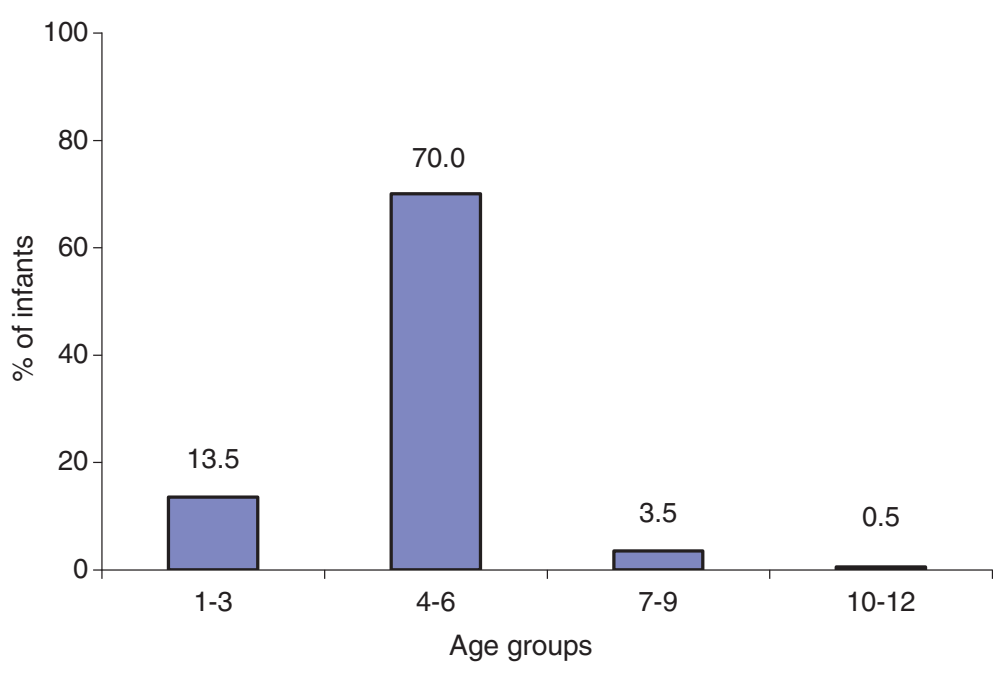

solid food was introduced

Figure 1 Percentage of infants receiving solid foods for the first time in different age groups. 
Table 5 Mean age at which each of the complementary food was added

\begin{tabular}{lcccc}
\hline Complementary food & Mean age \pm SD & Median & Min & Max \\
\hline Formula milk & $3.8 \pm 3.8$ & 3.00 & 1 & 24 \\
Home made cereal & $4.9 \pm 1.7$ & 4.00 & 1 & 13 \\
Ready-made cereal & $4.6 \pm 1.1$ & 4.00 & 2 & 12 \\
Fruits & $5.1 \pm 1.6$ & 5.00 & 2 & 13 \\
Vegetables & $5.9 \pm 2.5$ & 5.00 & 3 & 24 \\
Legumes & $7.8 \pm 2.6$ & 7.00 & 3 & 18 \\
Eggs & $7.4 \pm 2.1$ & 7.00 & 3 & 18 \\
Meat & $8.8 \pm 3.1$ & 8.00 & 3 & 24 \\
Chicken & $8.6 \pm 2.9$ & 8.00 & 3 & 24 \\
Fish & $9.1 \pm 3.3$ & 8.00 & 4 & 24 \\
\hline
\end{tabular}

respectively. Fruits and vegetables were introduced at a mean infant age $( \pm \mathrm{SD})$ of $5.1 \pm 1.6$ months, and $5.9 \pm 2.5$ months respectively. Legumes and eggs were given to the infants at about 7 months, while meat and chicken were introduced at the age of about 8 months. Fish was introduced later on average at 9 months.

\section{Reasons for termination of breastfeeding}

Mothers in this study were asked why they stopped breastfeeding. The main reasons for stopping breastfeeding as stated by the mothers were mainly new pregnancy and breastmilk insufficiency. Some mothers said that they terminated breastfeeding because they got pregnant again (32.9\%; $n=77)$, while about $24.4 \%(n=57)$ of the mothers stopped breastfeeding because they said they did not have sufficient breast milk. Others said that the child refused to continue breastfeeding (24.4\%; $n=57)$. This reason could also be related to breastmilk insufficiency because may be the child refused to continue breastfeeding because there was not sufficient breastmilk to satisfy his hunger. Other reasons for terminating breastfeeding were child's reaching weaning age $(6.0 \% ; \mathrm{n}=14)$ and mother's sickness $(5.6 \%$; $\mathrm{n}=13$ ). Mother's refusal, infant sickness and mother's returning to work were reported by $6.8 \%(n=16)$ of the interviewees as the reasons behind stopping breastfeeding.

Mothers in this study followed different methods for terminating breastfeeding. Half of them $(n=86,50 \%)$ physically distanced themselves from their infants. Some even said that they had sent their children to relatives, most often the children's grandparents, for several days. Others $(n=43,25 \%)$ started introducing formula milk so their children would get used to it. While some of the mothers $(n=43,25 \%)$ rubbed their nipples with lipstick or a bitter substance called "sabr" so that the infant would dislike breastfeeding.

\section{Discussion and conclusion}

The UAE have embraced the WHO recommendations, and the Ministry of Health issued an infant feeding policy which recommends six months of exclusive breastfeeding. However, translation of these policies into action in the UAE would require immense planning and strong implementation programmes and strategies. Despite many efforts and plans to promote breastfeeding in the UAE, there are no clear national targets, strategies or action plans to protect, promote and support appropriate feeding practices of infants and young children. The UAE should plan an infant feeding policy in the context of WHO/ UNICEF Global Strategy for Infant and Young Child Feeding (IYCF) [19]. IYCF reported that once a strategy and an action plan are put in place, then countries will be able to proceed steadily and measure their progress towards established targets.

There are several limitations that need to be considered when interpreting the results of this study. One important limitation of this study is recall bias due to the retrospective nature of the data collection, possibly resulting in over or under estimation of actual breastfeeding practices. Although recall biases cannot be avoided, the author conducted all interviews to ensure consistent technique and interpretation of the answers. It should be also noted that epidemiological studies of this kind do not establish causality but may suggest associations.

Another limitation of this study is the representation of all the Emirati women who had babies and breastfeeding during the period of research. The generalisability of the results is limited by the element of convenience sampling - samples were drawn at the $\mathrm{MCH}$ and $\mathrm{PHC}$ clinics, which increase the likelihood of some types of people being selected rather than others. However, (a) strong attempts were made to match the demographic characteristics of the general population of mothers, and (b) a large proportion (more than 90\%) of Emirati mothers do use the clinics for following up with the vaccination programs of their infants, as required by the Ministry of Health.

The findings in this study showed that initiation time of the first breastfeed of the whole population studied was high (98\%). Although this high initiation rate is encouraging compared to Western countries, the premature introduction of supplementary feeds, the early cessation of breastfeeding and failure to exclusively breastfeed are great concerns. Despite the efforts of the Ministry of Health and the Health Education programs on breastfeeding, many participants still introduced either prelacteal fluids or supplementary food before the infant reached six months of age.

A number of socio-demographic variables were associated with the initiation and duration of breastfeeding in this study. In general, multiparous mothers were likely to initiate and exclusively breastfeed for longer periods than 
primiparous mothers. The association of parity with breastfeeding initiation, exclusivity and duration was investigated in several studies and similar results were reported [20-22]. However, education as a predictor differs between developing and developed countries. Educated mothers in most developed countries have returned to breastfeeding $[23,24]$ while in developing countries, mothers with high education have increasingly switched to bottle feeding or mixed feeding [25,26].This finding has been explained by Abada et al. [27] that higher education in developing countries is associated with the adoption of modern ideas, often leading to the abandonment of traditional practices such as breastfeeding.

Although the majority of Emirati mothers, in this study, breastfed their infants, only $25 \%$ of them were exclusively breastfed for six months. Similarly, low levels of exclusive breastfeeding were recorded in other countries [28-30]. Higher rates of exclusive breastfeeding have been reported in New Zealand [31] and Norway [32], where $42 \%$ of the infants were exclusively breastfed for 4 months. However, even in these countries, exclusive breastfeeding declined to $7 \%$ at six months of age. This means that there still exists a need for encouraging mothers to continue exclusive breastfeeding till the infants are 6 months old.

Providing children with water as early as one month of the infant's age, is a normal practice in UAE as well as many other communities [33-35]. Emirati mothers justified this practice by stating that the UAE have a hot climate, and infants need to be hydrated. Early supplementation with formula milk and other liquids was also noted in this study. It should be mentioned that breast milk alone can maintain adequate water balance in young infants and supplementary fluids are not needed even in warm climates [36,37].

Caesarean delivery, contraception and nipple problems were reported in this study as influencing variables associated with breastfeeding practices. These factors have previously been shown to hinder breastfeeding and disrupt lactation [38-40].

Multiple logistic analysis of breastfeeding patterns indicated that rooming in, number of breastfeeds at night and breastfeeding on demand were the most significant predictors influencing breastfeeding patterns. Rooming in encourages demand and night feeding, and this allows frequent and close contact between the mother and the baby [41]; it also encourages the establishment of longer duration of exclusive breastfeeding [42,43].

Timely introduction of solid foods remains an important factor for healthy infant growth. The premature introduction of complementary food was of great concern in the present study. Despite the efforts of the UAE national health education programs, many participants still introduced complementary food before the baby reached six months of age. Musaiger [9] revealed that weaning foods are introduced very early in all Arabian Gulf countries. This was attributed to high purchasing power and the wide availability of commercial baby foods. Research suggested that complementary foods offered to infants before 6 months of age tend to displace breastmilk without conferring any growth advantage over exclusive breastfeeding [44]. Early introduction of other foods or drinks is an area of concern mainly because it marks the end of exclusive breastfeeding which has protective effects [45].

In the present study, the most frequently reported reason for starting weaning and terminating breastfeeding was that the mother became pregnant (32.9\%). This reason was also recorded by other studies for discontinuing breastfeeding [46-48] The belief that the breast milk of pregnant women could be harmful or no longer nutritious is widely common among Gulf women [9] and women from other communities $[49,50]$.

Other participants, in this study, stated that they stopped breastfeeding and started formula feeding because they believed that their breastmilk was insufficient and infant refused to suck. There seems to be a widespread perception of lactation insufficiency reported by other studies, and accordingly, the infant is given supplements at a very early age $[42,51]$. The mother's concern about milk insufficiency could be explained by her poor understanding of the proper techniques to increase breastmilk. Contrary to this belief, most mothers are able to produce breastmilk in quantities adequate for the proper growth of their infants, even in societies where the mother's diet is poor [38]. Daly and Hartmann [52] revealed that maternal milk production is finely tuned to the demand of the infant. Therefore, frequent and exclusive breastfeeding is critical for stimulating optimal milk production.

The results of this study suggest an urgent need to target breastfeeding education campaigns at young, primiparous, which either completed high school or higher education. Those mothers were identified by this study as the most vulnerable group who are at risk of not exclusively breastfeeding. So proper advice and breastfeeding management are required to increase awareness of exclusive breastfeeding benefits and to ensure that the problems Emirati mothers face during breastfeeding do not lead to the cessation of breastfeeding.

The promotion of breastfeeding can be a potential component of the primary public health strategies to decrease public health problems in the UAE, such as obesity and NCD's and their related risk factors. This will contribute to improving the health, nutrition and wellbeing of both infants and mothers.

Moreover, the findings of this study should be the foundation of future studies that investigate the feeding patterns in the UAE, and eventually assist in creating a 
national infant feeding policy. There is a need for a larger more detailed study following women from before birth until they stop breast feeding their babies, the thoughts and feelings of the mother and her social networks at each stage of the process should be explored.

\section{Competing interests}

The author declares that she has no competing interests.

\section{Authors' contributions}

HR designed the research, collected and analyzed data, and drafted the manuscript.

\section{Acknowledgments}

We thank Miss Nada Adra from the American University of Beirut and Mr. Hussain Qazaq from the Community Nutrition Dept,-Tawam Hospital for their technical assistance. We also thank Mrs. Nada Al Adib from the Community Nutrition Dept-Tawam Hospital, Mrs. Kariman Bozo from the Health Education Department in the Dubai Medical District and Mrs. Fatima Juneid from Al Wasl hospital for their assistance in facilitating the data collection. We thank also Dr. Taoufik Zoubeidi from UAE University for his assistance in the statistical analysis.

Received: 26 June 2012 Accepted: 13 February 2013

Published: 25 February 2013

\section{References}

1. Kramer MS, Chalmers B, Hodnett E, Sevkovskaya Z, Dzikovich I, Shapiro S, et al: Promotion of breastfeeding intervention trial (PROBIT): a randomized trial in the Republic of Belarus. JAMA 2001, 285:413-420

2 UNICEF: State of the World's Children. UNICEF; 2008

3. Musaiger AO: Overweight and obesity in the Eastern Mediterranean Region: can we control it? East Mediterr Health J 2004, 10(6):789-93.

4. WHO: Global Strategy for Infant and Young Child Feeding. Geneva: WHO; 2003.

5. Gillman MW: The first months of life: a critical period for development of obesity. AJCN 2008, 87(6):1587-1589.

6. Arenz S, Ruckerl R, Koletzko B, von Kries R: Breast-feeding and childhood obesity: a systematic review. Int J Obes Relat Metab Disord 2004, 28:1247-1256.

7. Horta BL, Bahln R, Martines JC, Victora CG: Evidence on the long- term effects of breastfeeding: systematic reviews and meta-analyses. Geneva: WHO; 2007:52-57.

8. Ip S, Chung M, Raman G, Chew P, Magula N, DeVine D, Trikalinos T, Lau J: Breastfeeding and maternal and infant health outcomes in developed countries. Evidence Reports/Technology Assessments, No. 153. AHRQ Publication No. 07-E007. Rockville, MD: Agency for Healthcare Research and Quality; 2007.

9. Musaiger AO: Breastfeeding Patterns in the Arabian Gulf Countries. World Rev Nutr Diet 1995, 78:164-190.

10. Harfouche JK: Breast-feeding patterns: a review of studies in the Eastern Mediterranean Region. Alexandria: World Health Organization, Eastern Mediterranean Regional Office, EMRO Technical publications Series, No.4; 1982.

11. Balo NM, Shembesh NM, Singh R: Maternal characteristics and infant and young child feeding in Benghazi. East Mediterr Health J 1996, 2(3):432-439.

12. Autret M, Miladi S: Report on the state of food and nutrition in the United Arab Emirates. Part II. UNICEF; 1979.

13. National Nutrition Survey: UAE Ministry of Health. UAE; 1992.

14. Al-Mazroui MJ, Oyejide CO, Bener A, Cheema MY: Breastfeeding and supplemental feeding for neonates in Al-Ain, United Arab Emirates. J Trop Pediatre 1997, 43:304-306.

15. Osman N, El-Sabban F: Infant feeding practices in Al-Ain, United Arab Emirates. WHO 1999, 5:103-110.

16. Al Tajir GK, Sulieman HS, Badrinath P: Intragroup differences in risk factors for breastfeeding outcome in a multicultural community. I Hum Lact 2006, 22(1):39-47.

17. World Health Organization (WHO): Indicators for assessing infant and young child feeding practices Part 1Definitions. Geneva: WHO; 2008.
18. Labbok M, Krasovec K: Towards consistency in breastfeeding Definitions. Stud Fam Plann 1990, 21(4):226-230.

19. WHO: Planning Guide for national implementation of the Global Strategy for Infant and Young Child Feeding. Geneva: WHO; 2007.

20. Kronborg $\mathrm{H}$, Vaeth $\mathrm{M}$ : The influence of psychosocial factors on the duration of breastfeeding. Scand J Public Health 2004, 32(3):210-218.

21. Leung EY, Au KY, Cheng SS, Kok SY, Lui HK, Wong WC: Practice of breastfeeding and factors that affect breastfeeding in Hong Kong. Hong Kong Med J 2006, 12(6):432-436.

22. Amin T, Hablas H, Al Qader AA: Determinants of initiation and exclusivity of breastfeeding in Al Hassa, Saudi Arabia. Breastfeed Med 2011, 6(2):59-68.

23. Kassam-Lallanie D, Moynagh K, Ross H, Sellar L, Sigmundson C: Infant Feeding in Halton. Halton Regional Health Department; 2002.

24. Simard I, O'Brien HT, Beaudoin A, Turcotte D, Damant D, Ferland S, et al: Factors influencing the initiation and duration of breastfeeding among low-income women followed by the Canada prenatal nutrition program in 4 regions of Quebec. J Hum Lact 2005, 21:327-337.

25. Wilmoth TA, Elder JP: An assessment of research on breastfeeding promotion strategies in developing countries. Soc Sci Med 1995, 41(4):579-594

26. Morisky DE, Kar SB, Chaudhry AS, Chen KR, Shaheen M, Chickering K Breastfeeding practices in Pakistan. PJN 2002, 1(3):137-142.

27. Abada TS, Trovato F, Lalu N: Determinants of breast-feeding in the Philippines: a survival analysis. Soc Sci Med 2001, 52(1):71-81.

28. Marques NM, Lira PIC, Lima MC, Lacerda da Silva N, Filho MB, Huttly SRA, Ashworth A: Breastfeeding and early weaning practices in Northeast Brazil: a longitudinal study. Pediatrics 2001, 108(4):e66.

29. Awumbila M: Social Dynamics and infants feeding practices in Northern Ghana. Institute of African Studies: Res Rev 2003, 19(2):86-89.

30. Li R, Zhao Z, Mokdad A, Barker L, Grammer-Stravon L: Prevalence of breastfeeding in the United States: The 2001 National Immunization Survey. Pediatrics 2003, 111(5 part 2):1198-1201.

31. Heath AM, Tuttle CR, Simons MSL, Cleghom CL, Parnell WR: A longitudina Study of breastfeeding and weaning practices during the first year of life in Dunedin, New Zealand. J Am Diet Assoc 2002, 102(7):937-944.

32. Lande B, Anderson LF, Baerug A, Trygg KU, Lund-Larsen K, Veierod MB, Bjorneboe GE: Infant feeding practices and associated factors in the first six months of Life. The Norwegian Infant Nutrition Survey. Acta Paediatr 2003, 92:152-161.

33. Faber $\mathrm{M}$, Benade AJS: Nutritional status and dietary practices of 4-24 -month-old children from a rural South African community. Public Health Nut 1999, 2:179-185.

34. Engle PL: Infant feeding styles: barriers and opportunities for good nutrition in India. Nutrition Rev 2002, 50:S109-S114.

35. El Mouzan Ml, Al Omar AA, Al Salloum AA, Al Herbish AS, Qurachi MM: Trends in infant nutrition in Saudi Arabia: compliance with WHO recommendations. Ann Saudi Med 2009, 29(1):20-23.

36. Sachdev HPS, Krishna J, Puri RK, Satyanarayana SL, Kumar S: Water supplementation in exclusively breastfed infants during summer in the tropics. Lancet 1991, 337:929-933.

37. Almorth S, Bidinger PD: No need for water supplementation for exclusively breastfed infants under hot and arid conditions. Trans $R$ Soc Trop Med Hyg 1990, 84:602-4

38. Ruel MT, Menon P: Child feeding practices are associated with child nutritional status in Latin America: innovative uses of the demographic and health surveys. J Nutr 2002, 132:1180-1187.

39. Cernades JM, Nocada G, Barrera L, et al: Maternal and perinatal factors influencing the duration of exclusive breastfeeding during the first six months of life. J of Hum Lact 2003, 19(2):136-44.

40. Ogbeide DO, Siddiqui S, Al-Khalifa IM, Karim A: Breastfeeding in a Saudi Arabian community: profile of parents and influencing factors. Saudi Med J 2004, 25(5):580-584.

41. Batal M, Boulghouriian C, Abdalla A, Afifi R: Breast-feeding and feeding practices of infants in a developing country: a national survey in Lebanon. Public Health Nutr 2006, 3:313-319.

42. Scott JA, Landers MCG, Hughes RM, Binns CW: Factors associated with breastfeeding at discharge and duration of breastfeeding. JPCH 2001, 37:254-261.

43. Duong DV, Binns CW, Lee AH: Breastfeeding initiation and exclusive breastfeeding in rural Vietnam. Public Health Nutr 2004, 7(6):795-799. 
44. Dewey KG, Cohen RJ, Brown KH, Rivera LL: Effects of exclusive breastfeeding for four versus six months on maternal nutritional status and infant motor development: results of two randomized trials in Honduras. J Nutr 2001, 131:262-267.

45. Hornell A, Aarts C, Kylberg E, Hofvander Y, Gebre-Medhin M: Breastfeeding patterns in exclusively breastfed infants: a longitudinal prospective study in Uppsala, Sweden. Acta Paediatr 1999, 88(2):203-211.

46. Wayland C: Breastfeeding patterns in Rio Branco, Acre, Brazil: a survey of reasons for weaning. Cad Saude Publica 2004, 20(6):1757-1761.

47. Al Jassir MS, El-Bashir BM, Moizuddin SK, Abu-Nayan AAR: Infant feeding in Saudi Arabia: mothers' attitudes and practices. East Mediterr Health J 2006, 12(1\&2):6-13.

48. Haroun $\mathrm{H}$, Mahfour MS, Ibrabim BY: Breast feeding indicators in Sudan: a case study of Wad Medani town. SJPH 2008, 3(2):81.

49. Greiner T: Sustained breastfeeding, complementation and care. Food Nutr Bull 1995, 16:313-319.

50. Davies-Adetugbo AA: Sociocultural factors and the promotion of exclusive breastfeeding in rural Yoruba communities of Osun state. Nigeria Soc Sci Med 1999, 45(1):113-125.

51. Khassawneh $M$, Khader $Y$, Amarin Z: Knowledge, attitude and practice of breastfeeding in the north of Jordan: a cross-sectional study. Int Breastfeed J 2006, 1:17.

52. Daly SE, Hartmann R: Infant demand and milk supply: Part 1. J Hum Lact 1995, 11(1):21-37.

doi:10.1186/1471-2458-13-171

Cite this article as: Radwan: Patterns and determinants of breastfeeding and complementary feeding practices of Emirati Mothers in the United Arab Emirates. BMC Public Health 2013 13:171.

\section{Submit your next manuscript to BioMed Central and take full advantage of:}

- Convenient online submission

- Thorough peer review

- No space constraints or color figure charges

- Immediate publication on acceptance

- Inclusion in PubMed, CAS, Scopus and Google Scholar

- Research which is freely available for redistribution 